\title{
Urban mobile food truck policies: reducing disparities and building a culture of health in the United States
}

\author{
Edward V. Wallace ${ }^{1}$ (D)
}

Accepted: 29 December 2020 / Published online: 10 February 2021

(c) The Author(s), under exclusive licence to Springer Nature Limited part of Springer Nature 2021

\begin{abstract}
We undertook this study knowing that for people throughout the Midwest who live in low-income urban neighborhoods, finding and affording healthy foods continues to be a problem. People with less money are not only forced to spend it on food, but have so limited options for avoiding purchase of foods with high levels of fat, salt, and sugar. A review of the literature shows that very little is known about how mobile food trucks can increase availability and affordability of healthy foods in low-income neighborhoods in the United States. We compared municipal codes regulating mobile food truck operators and evaluated the impact on cities in the Midwest for encouraging a 'culture of health.' We analyzed six Midwest metropolitan areas with the highest proportion of minorities who lived below the poverty level and had mobile food trucks selling provisions in their neighborhoods. We found that developing more incentives for mobile food truck operators to sell healthier food options can contribute to improving health outcomes in low-income neighborhoods.
\end{abstract}

Keywords Policy $\cdot$ Food trucks $\cdot$ Disparities $\cdot$ Culture of health

\section{Introduction}

Nutritious, healthy food has been associated with reduction of chronic diseases such as obesity, diabetes, coronary heart disease, and strokes [1]. Availability of healthy foods for people who live in low-income urban neighborhoods continues to be a problem throughout the Midwest United States (US), despite introduction of green spaces and community gardens to these neighborhoods in recent years [2]. For people who live in low-income urban neighborhoods, finding healthy food to buy can be difficult and many low-income families struggle with food insecurity more often than the general population [3]. Data from the latest US Household Food Security

Edward V. Wallace

Edward.wallace@UC.edu

1 Africana Studies Department, University of Cincinnati, 3609 French Hall Department, French-West 3609, Cincinnati, OH 45221, USA 
Survey conducted in low-income areas asked the single question ("In the last twelve months were there any times that you couldn't afford food, or afford to buy more food, or ran out of food"?). Results showed higher rates of food insecurity among African Americans (14\%), renters of homes (rather than owners) (21\%), those who are unemployed (22\%), and single parent households (22\%) [4]. African Americans or other racial and ethnic groups often fall into several of these categories [5]. Research suggests that the most common denominator of food insecurity is poverty, placing some sub-groups at higher risk than others [6].

People with less money are not only forced to spend money on food which is less expensive and lack nutritional value; they also have less accessibility to fruits and vegetables because of cost, compared to those who have resources [7]. In addition, studies have shown that the lack of consumption of fruits and vegetables in foodinsecure urban neighborhoods is continuously associated with the worst health outcomes, such as diabetes, cardiovascular disease, and obesity [8, 9]. Evidence shows an association of insufficient consumption of healthy food with poor psychological functioning, increased risk of chronic diseases, increased body mass index, smoking, low educational level, and poor health outcomes $[10,11]$. Also, children from urban neighborhoods who reside in food-insecure households are at greater risk of behavioral and health problems [12].

Although socioeconomic status leads to less access to healthy foods, this factor is not the only one; people in low-income urban neighborhoods have difficulty finding healthy foods to eat. Healthy foods can be defined as a variety of foods that give person nutrients to maintain their health and boost their energy [13]. The role of the built environment must also be evaluated and criticized for its contribution to the problem. Many supermarkets in the inner city have closed to open instead in areas with lower risk of crime and theft, and more land for parking [14]. Supermarkets tend to stock and sell fresh produce, but presence of these items is less likely in low-income neighborhoods inhabited by vulnerable populations $[15,16]$. Closings of supermarkets and their owners' lack of interest in investing in urban areas have pushed people from underrepresented population to purchase foods and snacks from small and local 'corner stores' [17]. Although some studies demonstrate supermarkets in urban areas are increasing in numbers and improving their provisions of healthy fruits and vegetables, corner stores continue to be the primary source from which people in low-income neighborhoods purchase their food [18]. Many researchers in the public health sector have attempted to design, implement, and evaluate corner store improvement interventions. In Philadelphia Pennsylvania, researchers found that by advertising signs with fruits and vegetables outside of corner stores that there was an association between fruit and vegetable consumption compared to basic corner stores with no signage of fruits and vegetables [19]. Similarly, in Hartford Connecticut, researchers found that increasing the selection of fruits and vegetables and other healthy produce at corner stores changed shopping behavior and increased fruit and vegetable consumption among low-income residents [20]. These corner stores, however, only may serve a specific geographic area for people in low-income communities with limited transportation.

An alternative potential source for nutritious food can be food trucks that are mobile and less expensive for customers than corner stores. Food truck vendors offer 
a potential venue to increase food access and build a culture of health. A "culture of health' refers to working together to improve the health of all, ensuring that everyone has the opportunity to make choices that lead to healthy lifestyles [21]. Food truck vendors can easily provide healthy foods to underrepresented populations in entire neighborhoods, unlike local corner stores. Food truck vendors appear to be familiar with the people in the neighborhoods they serve, and often have relationships with their customers that allow them to promote the sale of nutritious foods [22]. In addition, food truck owners interact and engage with their customers in a very personal way. Selling food face-to-face helps owners gauge reactions as they learn about the communities they serve.

Our review of the literature shows that very little is known about how mobile food trucks can increase accessibility of healthy foods. Permits and licenses for food trucks vary from state to state and city to city. Cities in the Midwest, however, are beginning to share common licenses and permits. Our goal is to study municipality regulations to see if urban mobile food trucks can build a culture of healthy eating in metropolitan areas in the Midwest. Healthy food policies, and in particular mobile food truck policies, have become more prevalent in recent years in the United States and internationally. This paper presents a review of 6 cities' municipal codes relevant to food trucks; we identify and examine policies on the city's own websites, and discuss the contents of the documents and their potential contribution to building a 'culture of health.'

\section{Methods}

The study team consists of the author with assistance from graduate students. The author conceptualized the research idea, supervised graduate students, managed the data, and prepared manuscript.

We studied municipal codes of six cities in the Midwest, United States 2018-2019 to

- learn if all food trucks were required to operate from a commissary and subject to inspection

- understand how licenses and costs helped or hindered the selling of healthy foods such as fruits and vegetables

- identify if there were any restrictions on how many times a vendor could stop to sell food

- understand how six cities are building a culture of health.

We analyzed six metropolitan areas in the Midwest (Chicago, Detroit, Cleveland, Cincinnati, St. Louis, Milwaukee) as defined by the U.S. Census Bureau. We used the criteria of race, ethnicity, socioeconomic status, and size of population, to select these cities for the study [23].

Between February and May of 2019, the team reviewed policies that addressed food truck vendors' compliance with polices requiring each to have a permit, ensure that food is safe, specify a geographical location or route for their truck, and promote 
healthy food options. [24]. We used 35 search words referring to mobile food trucks, and we added "street food," "food service truck," and "restaurant on wheels" as these phrases are used by scholars as alternative key words in database searches. After identifying all possible municipal codes and policies, we stopped searching when we reached the 'saturation point,' meaning we discovered no new information.

\section{Results}

Using municipal codes for food truck operators in six Midwest cities, we describe results for health, including protection of food, vendors' licenses to operate and sell and associated costs, geographical location, and food encouragement. Food encouragement is when incentives are given to food truck owners for encouraging their customers to make smart food choices (i.e., fruits, whole grains, and vegetables) when they purchase food [25].

For health and protection of food we found that all of the selected cities in the Midwest, Chicago, Detroit, Cleveland, St. Louis, Cincinnati, and Milwaukee had mandated food trucks to operate from a commissary, which is subject to inspection by the local health department, Table 1. Commissaries are centralized locations where food truck vendors are responsible for cleaning, storing, and sanitizing their vehicles and equipment [26]. For licenses and costs, our results showed that municipal regulations require city food truck operators to obtain a license before selling food to the public. As to geographical location, results showed that only Detroit imposed restrictions on the hours during which food truck operators could make stops to sell food (Table 1). We also found Detroit was the only city that required food truck operators to sell food on private property.

Results for 'food encouragement' showed that only three of the six cities, Detroit, Cleveland, and St. Louis required food truck operators to offer at least one 'healthy meal' in the communities that they serve. According to Healthy Eating Guidelines (2020), a healthy meal is defined as not depriving yourself of the foods that you love, but rather eating specific nutrients that have been shown to improve your health and provide energy to meet your daily tasks [27]. We found different approaches for food encouragement in Chicago and Milwaukee. In Chicago, food truck vendors who sell healthy foods (i.e., fruits and vegetables) paid a reduced licensing fee (Table 1).

\section{Discussion}

We examined four components of municipal regulations in six select cities, to see if urban mobile food trucks could build a culture of health in the Midwest. Our analysis demonstrated that all of the cities require food truck operators to operate from a commissary to protect the health and the safety of the food. The possibility of building a 'culture of health' in the Midwest is well within reach because local governments support food trucks by helping the food truck operators maintain safe commissaries. The local government is also showing their support by paying the cost of licensing fees for the food truck operators. In addition, the 


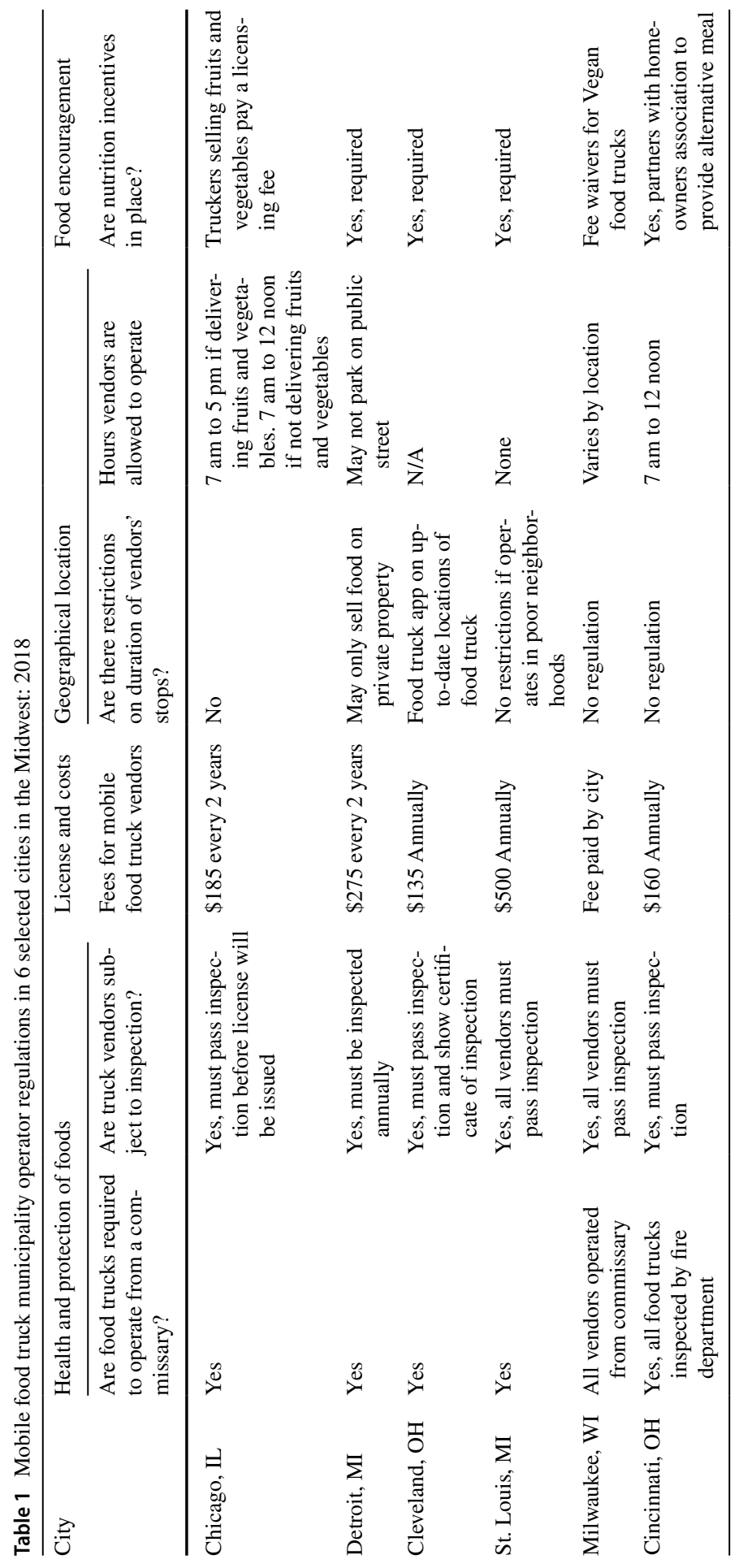


local government is purchasing food from distributors to food truck operators and is committed to continuing these efforts for food truck operators.

Municipalities could increase sale and consumption of nutritious foods and reduce that of sugary drinks such as sodas and fruit juices. Local policy makers could allow mobile food truck operators who provide nutritious meals (including fruits and vegetables) and drinks with no sugar, such as bottled water in lowincome communities to qualify for free inspection of the food vendors' trucks. In Columbus, Ohio, stakeholders and local policy makers are in the early stages of implementing a policy to support only selling bottled water on trucks and no beverages that contain sugar. If and when this municipal regulation goes into effect, it will signify an effort to reduce sugary drink consumption among people of color and, more generally, the influence that municipal regulations have on populations [28]. Policy makers in the selected cities also determined it was crucial for food truck operators to pay a fee for a license. These licenses, however, should not be viewed as barriers to these operators because policy makers have allowed waiving licensing fees for food truck venders if they accept state welfare benefits, such as the Supplement Nutrition Assistance Program (SNAP). The SNAP program uses a plastic card that looks like a debit card, which allows people to buy groceries and other items from stores and other locations [29]. In St. Louis, a food truck owner and operator willing to travel to low-income communities and accept state welfare benefits is allowed a waiver that exempts that person from payment of the licensing fee of $\$ 500$ (Table 1) [30]. To monitor and ensure actual sales are taking place using welfare benefits, food truck operators use debit card machines to keep track of debit card transactions. This allows people from low-income communities to stretch their food budgets by using their welfare benefits cards to purchase healthy foods instead of using cash.

Policy makers are increasing the number of future food truck entrepreneurs by encouraging mentorships with individuals from their local communities and their families. Milwaukee, Wisconsin encourages food truck operators to mentor people in low-income communities and help them to become entrepreneurs and operate their own small food truck businesses. For their participation, the city of Milwaukee will waive the $\$ 130$ licensing fee otherwise required for food truck operators (Table 1) [31]. Arizona State University offered a mentorship and training for food business entrepreneurs to encourage participants to start new food truck businesses. A study of this program showed that ninety-five percent of these entrepreneurs were African American who lived in low-income communities, and forty percent of entrepreneurs were women who succeeded in the program and began to operate their own food truck businesses [32].

One city had geographical location restrictions for food truck operators. Detroit required food truck operators to sell food on private property. This municipal regulation is good for people who live in low-income communities because there are no time restrictions for when food trucks may be on site to sell. Food truck operators that sell healthy foods such as fruits and vegetables on private property can compete more effectively against local corner stores and gas stations that tend to stay open 24-h a day selling unhealthy processed foods. This initiative illustrates how one city is attempting to compete with corner stores and promote healthy choices. 
Cities in the Midwest are building a culture of health by providing incentives to food truck operators who encourage communities to buy and eat healthy food. Chicago will waive food truck operators' licensing fees if they sell healthy meals to lowincome communities. More incentives for mobile food truck operators to sell safe and healthy foods could help to establish a culture of health, not only in the U.S. but also in other countries where our findings could be of interest given the magnitude of suffering from food insecurity and lack of healthy foods. A study in Australia focused on the role of mobile fresh fruit and vegetable trucks among people seeking asylum in Australia. Results showed that participants in the study (asylum seekers) experienced food insecurity and highly valued the presence of mobile food trucks. The study also identified mobile food trucks as a positive social setting for study participants [33]. We suspect that cities we studied can be leaders in educating others in the U.S. and abroad about the importance of having safe mobile food trucks, particularly with regard to sanitary inspection. A study in Brazil evaluated the application of good hygienic-sanitary practices in food trucks. Results showed that only one food truck out of ten met the requirement for having hygienic-sanitary practices, recommending more education on sanitary practices for food truck operators in Brazil [34].

The study has several limitations. We may have missed some relevant municipal codes even though several search rounds repeatedly produced the same municipal codes for the cities in the research study. We also view how we mention certain words in our study as a limitation. For example, the use of several words in the manuscript such as "healthy foods," "underrepresented populations," and "nutritious foods" can vary in definition and can be interpreted differently by various groups and in various parts of the world.

While our study preceded COVID-19, there is some information that is worth sharing about benefits of food trucks. The COVID-19 Pandemic has done something remarkable that no virus up to this point has done before, that is, to reveal disparities in access to healthy foods in the United States (U.S.) and internationally. The way we provide access and distribute healthy food worldwide is flawed. Food trucks are one of the few, if not the only food service that has been able to function to provide food safely during a global pandemic. In this new era of living with COVID-19, food trucks offer a possible solution to food insecurity in low-income families. Food trucks already exist in an outdoor setting making it easy for people to social distance. They provide a level of protection between the consumer and the chef, and occupy a better position to boost the economy by keeping the food truck operator employed (unlike dine-in restaurant staff) and people in the community fed. People can walk up to the food truck order food and sit outside to eat. Mobile food truck vendors are beginning to gain some attention in the public health literature in the United States and internationally.

\section{Conclusion}

Because there are no long-term studies in the literature on benefits of changing municipal regulations and providing incentives for food truck operators, we cannot conclude that because local governments in cities in the Midwest implemented 
changes to municipal laws for food truck operators that these will automatically produce a culture of health. We recommend that future studies evaluate these policies in greater detail. However, there is already sufficient evidence to support our argument that changes to municipal regulations for food truck operators constitute an important step toward improving health outcomes, reducing health disparities, and promoting health and well-being. Our study illustrates that bringing healthy foods to low-income communities and promoting a culture of health in the Midwest and globally will require sustained efforts [35]. Mobile food trucks can play a crucial role in promoting a culture of health for people in low-income communities. But only if we align and support policies that allow food truck operators to be successful can the promise become reality, in the United States and globally. The potential benefits appear to be magnified by the experiences during the COVID-19 pandemic.

\section{Definition of selected terms}

Vegan meals: meals that exclude meat, eggs, dairy products, and all other animalderived ingredients

Nutritious food: food that does not increase poor health outcomes when consumed by an individual.

Underrepresented populations: a certain group of people that differs from the majority population (i.e., Blacks, Hispanics, Asians, Native Americans, person with disabilities, Women).

Culture of health: it refers to working together to improve the health of all, ensuring that everyone has the opportunity to make choices that lead to healthy lifestyles.

Food encouragement: when incentives are given to food truck owners for encouraging their customers to make smart food choices (i.e., fruits, whole grains, and vegetables) when they purchase food.

Commissaries: centralized locations where food truck vendors are responsible for cleaning, storing, and sanitizing their vehicles and equipment.

Supplement Nutrition Assistance Program (SNAP): The SNAP program uses a plastic card that looks like a debit card, which allows people to buy groceries and other items from stores and other locations.

State welfare benefits: a federally funded, state-run program that helps families achieve independence after experiencing temporary difficulties.

Acknowledgements I would like to thank Derrick Jenkins and Shemika Jones for their hard work and dedication to this project.

\section{References}

1. Agudo A, Cabrera L, Amiano P, Barricarte A, Berenguer T, et al. Fruit and vegetable intakes, dietary antioxidant nutrients, and total mortality in Spanish adults: findings from the Spanish cohort of 
the European Prospective Investigation into Cancer and Nutrition (EPIC- Spain). Am J Clin Nutr. 2007;85:1634-42.

2. Chavez N, Telleen S. Food insufficiency in urban Latino families". J Immigr Minor Health. 2007;9:197-204.

3. Alvares L, Amaral FT. Food insecurity and associated factors in the Portuguese population. Food Nutr Bull. 2014;35(4):395-402.

4. US Department of Agriculture. Economic research Service. Economic drivers of fresh produce lost at the farm and pre-retail sectors [Internet]. Washington (DC). http://www.ers.usda.gov/media /884525/err141. Accessed 27 Jan 2020.

5. Shackman G, Chengxuan Y, Edmunds LS, Clarke L, Sekhobo JP. Relation between annual trends in food pantry use and long-term unemployment New York State, 2002-2012. Am J Public Health. 2015;105(3):63-5.

6. Pessoa MC, Mendes LL, Gomes CS, Martins PA, Melendez GV. Food environment and fruit and vegetable intake in a urban population: a multilevel analysis. BMC Public Health. 2015;15:1-8.

7. Haque MA, Farzana FD, Sultana S, Raihan MJ, Rahman AS, Waid JL, Ahmed T. Factors associated with child hunger among food insecure households in Bangladesh. BMC Public Health. 2017; $17: 1-178$.

8. Robaina KA, Martin KS. Food insecurity, poor diet quality, and obesity among food pantry participants in Hartford, CT. J Nutr Educ Behav. 2013;3:159-64.

9. Chinnakali P. Prevalence of household-level food insecurity and its determinants in an urban resettlement colony in north India. J Health Promot Nutr. 2014;32:2-22.

10. Jernigan VB, Wetherill MS, Hearod J, Jacob T, Salvatore AL, Cannady T, Buchwald D. Food insecurity and chronic diseases among American Indians in rural Oklahoma: the THRIVE Study. Am J Public Health. 2017;107(3):441-6.

11. Goldberg SL, Mawn BE. Predictors of food insecurity among older adults in the United States. Public Health Nurs. 2015;32(5):397-407.

12. Kirkpatrick SI, Tasrasuk V. Food insecurity associated with nutrient inadequacies among Canadian adults and adolescents. J Nutr. 2008;13:604-12.

13. Centers for Disease Control and Prevention. Healthy Eating for a Healthy Weight [Internet]. Atlanta (GA). https://www.cdc.gov/healthyweight/healthy_eating/index.html. Accessed 9 Nov 2020.

14. Pothukuchi K. Attracting supermarkets to inner-city neighborhoods: economic development outside the box. Econom Dev Q. 2005;19:232-44.

15. Powell L, Slater S, Mirtcheva D, Chaloupka F. Food store availability and neighborhood characteristics in the United States. Prev Med. 2007;102:216-9.

16. Jones P, Bhatia R. Supporting equitable food systems through food assistance at farmers' markets. Am J Public Health. 2011;101:781-3.

17. Moreland K, Wing S, Diez-Roux A, Poole S. Neighborhood characteristics associated with the location of food stores and food service places. Am J Prev Med. 2002;22:23-9.

18. Kaufman R. Rural poor have less access to supermarkets, large grocery stores". Rural Dev Perspect. 1999;13:19-26.

19. Cavanaugh E, et al. Changes in food and beverage environments after an urban corner store intervention. Prev Med. 2014;65:7-12.

20. Martin KS, et al. If you stock it, will they buy it? Healthy food availability and customer purchasing behavior within corner stores in Hartford, CT, USA. Public Health Nutr. 2012;15:1973-8.

21. Robertwood Johnson. Building a culture of health. https://www.rwjf.org/en/cultureofhealth/about .html. Accessed Nov 2020.

22. Tester J, Stevens S, Yen I, Laraoa B. An analysis of public health policy and legal issues relevant to mobile food vending. Am J Public Health. 2010;100:2038-46.

23. U.S. Census Bureau. Race and ethnicity in the mid-west. https://statisticalatlas.com/region/Midwest/ Race-and-Ethnicity. Accessed 19 Dec 2019.

24. Hunger and Health Feeding America. Foods to encourage background. [Internet]. https://hunge randhealth.feedingamerica.org/resource/foods-to-encourage-background/. Accessed 17 Dec 2020.

25. Change Lab Solutions. Columbus takes a stand for kids health. [Internet]. Oakland (CA). https:// www.changelabsolutions.org/story/columbus-takes-stand-kids-health. Accessed 17 Jan 2020.

26. Healthy Eating Guidelines. Healthy eating. [Internet]. https://www.helpguide.org/articles/healthyeating/healthy-eating.htm. Accessed May 2020.

27. City of Milwaukee. License and permits mobile truck sellers. https://city.milwaukee.gov/cityclerk/ license/LicensesPermits\#.XhocrK2B0dU. Accessed 13 Jan 2020. 
28. Department of Agriculture. Food and nutrition service [Internet]. Washington DC. https://www.fns. usda.gov/snap/supplemental-nutrition-assistance-program. Accessed April 2019.

29. Centers for Disease Control. Mobile food retailers. Encouraging food trucks to operate in underserved areas. [Internet]. Atlanta (GA): CDC; 2104 Nov. https://www.cdc.gov/nccdphp/dnpao/state -local-programs/pdf/Healthier-Food-Retail-guide-chapter-5.pdf. Accessed 6 Jan 2020.

30. Food Empowerment Project. Food deserts. [Internet]. Cotati (CA). https://foodispower.org/acces s-health/food-deserts/. 15 Jan 2020.

31. Arizona State University. https://entrepreneurship.asu.edu/community/prepped. Accessed 14 July 2020.

32. Haines BC, McKay FH, Dunn M, Lippi K. The role of social enterprise in food insecurity among asylum seekers. Health Soc Care Commun. 2018;26(6):829-38.

33. Bandeira Barbosa L, da Rocha Motreira M, Silva Lustosa IB, Rodrigues Brito FC, Silva de Sousa VS, de Almeida Cabral L. Evaluation of good-hygienic sanitary practices in food trucks. Motricidade. 2018;14(1):226-31.

34. Department of Agriculture and Development for Michigan. Food services licensing details. [Internet]. Lansing (MI). https://www.michigan.gov/mdard/0,4610,7-125-1569_16958_16977-17400 8-,00.html. Accessed 3 Jan 2020.

35. American Planning Association. Regulating food trucks. https://planning-org-uploaded-media.s3. amazonaws.com/document/open-EIP36.pdf. Accessed 21 Dec 2019.

Publisher's Note Springer Nature remains neutral with regard to jurisdictional claims in published maps and institutional affiliations.

Edward V. Wallace , PhD, MPH, is an Associate Professor in the Africana Studies Department at the University of Cincinnati, Cincinnati, Ohio, 45221, USA. 